\title{
Waist circumference and waist-to-height ratio of Hong Kong Chinese children
}

\author{
Rita YT Sung*1, Hung-Kwan So ${ }^{1}$, Kai-Chow Choi ${ }^{2}$, Edmund AS Nelson ${ }^{1}$, \\ Albert M Li ${ }^{1}$, Jane AT Yin ${ }^{1}$, Charlotte WL Kwok ${ }^{1}$, Pak-Cheung Ng${ }^{1}$ and Tai- \\ Fai Fok ${ }^{1}$
}

\begin{abstract}
Address: ${ }^{1}$ Department of Paediatrics, The Chinese University of Hong Kong, Hong Kong Special Administrative Region, the People's Republic of China and ${ }^{2}$ Centre for Clinical Trials and Epidemiological Research, The Chinese University of Hong Kong, Hong Kong Special Administrative Region, the People's Republic of China

Email: Rita YT Sung* - yntzsung@cuhk.edu.hk; Hung-Kwan So - sohk@cuhk.edu.hk; Kai-Chow Choi - kchoi@cuhk.edu.hk; Edmund AS Nelson - tony-nelson@cuhk.edu.hk; Albert M Li - albertmli@cuhk.edu.hk; Jane AT Yin - jane-yin@cuhk.edu.hk; CharlotteWL Kwok - charlott.kwok@gmail.com; Pak-Cheung Ng - pakcheungng@cuhk.edu.hk; Tai-Fai Fok - taifaifok@cuhk.edu.hk

* Corresponding author
\end{abstract}

Published: 22 September 2008

BMC Public Health 2008, 8:324 doi:I0.1 186/147I-2458-8-324

This article is available from: http://www.biomedcentral.com/147I-2458/8/324

(c) 2008 Sung et al; licensee BioMed Central Ltd.

This is an Open Access article distributed under the terms of the Creative Commons Attribution License (http://creativecommons.org/licenses/by/2.0), which permits unrestricted use, distribution, and reproduction in any medium, provided the original work is properly cited.

\begin{abstract}
Background: Central body fat is a better predictor than overall body fat for cardiovascular (CV) risk factors in both adults and children. Waist circumference (WC) has been used as a proxy measure of central body fat. Children at high CV risk may be identified by WC measurements. Waist-to-height ratio (WHTR) has been proposed as an alternative, conveniently age-independent measure of $\mathrm{CV}$ risk although WHTR percentiles have not been reported. We aim to provide ageand sex-specific reference values for WC and WHTR in Hong Kong Chinese children.
\end{abstract}

Methods: Cross sectional study in a large representative sample of 14,842 children aged 6 to 18 years in 2005/6. Sex-specific descriptive statistics for whole-year age groups and smoothed percentile curves of WC and WHTR were derived and presented.

Results: WC increased with age, although less after age 14 years in girls. WHTR decreased with age (particularly up to age I4). WHTR correlated less closely than WC with BMI ( $r=0.65,0.59$ cf. $0.93,0.91$, for boys and girls respectively).

Conclusion: Reference values and percentile curves for WC and WHRT of Chinese children and adolescents are provided. Both WC and WHTR are age dependent. Since the use of WHRT does not obviate the need for age-related reference standards, simple WC measurement is a more convenient method for central fat estimation than WHRT.

\section{Background}

Central obesity in both adults [1-3] and children [4-6] is related to cardiovascular (CV) risk factors (hyperlipidemia, insulin resistance and hypertension). Waist circumference (WC) and WC-derived indices such as waist- to-hip ratio and waist-to-height ratio (WHTR) have been used as proxy measures of central obesity, the former being widely used in adults $[7,8]$. There is growing evidence however that waist circumference (WC) alone correlates more strongly than waist-to-height ratio (WHTR) 
with CV risk, in adults [2] as well as in children [9-11]. Previous studies have shown that adults from a number of South and East Asian countries are predisposed to central obesity and insulin resistance $[12,13]$. This ethnic difference of increased body fat distribution in the trunk region has also been observed in adolescents [14] and prepubertal children [15] of mainly East Asian origin, highlighting the importance of ethnic-specific studies.

Standard WC cutoffs for high CV risk have been proposed for adults [16-18] and are widely used, but measurement of WC is not yet common practice in growing children. Age-related percentiles have been reported for children from a number of different countries: Italy [19]; Spain [20]; Cyprus [21]; United Kingdom [22]; Canada [23]; USA [24]; Holland [25]; Australia [26]; and Iran [27] (Table 1), but, to our knowledge, the only published WC data in Chinese children in the English literature is our relatively small study of 6 to 12 year old children [11], drawn from the same population as the present study.

WHTR has been proposed as a convenient alternative measure for assessing central fatness in children, on the basis that it is relatively age-independent and that in normalising for growth it might obviate the need for agerelated reference charts [28-30]. "Keep your waist circumference to less than half your height" (i.e. WHTR 0.5) is a seductively simple target [31]. However WHTR percentiles have not been reported and the generality of its independence of ethnic and age differences is questionable.

In 1993 a growth survey of 25,000 Hong Kong children from birth to $18 \mathrm{y}$ was undertaken and growth charts for weight, height, weight-for-height and body mass index were developed [32]. WC was not measured. We now report a further growth study of 14,842 ethnic Chinese children aged 6 to 18 y undertaken in 2005/2006, using similar methods but including WC measurement to provide reference values for WC and WHTR.

\section{Methods \\ Sampling method}

A list of all schools in Hong Kong was compiled from data held by the Department of Education. One primary school and one secondary school were selected randomly from each of the 18 Districts in Hong Kong. Two classes in each grade were then selected. (see article on "Secular changes in height, weight and body mass index in Hong Kong Children" for further details). All students of the selected classes were invited to join the study. A fact sheet explaining the purpose and procedure was given to each student and their parents. Seven percent of the primary and $10 \%$ of the secondary school students declined to participate. The parents of all participants were invited to complete a questionnaire providing demographic information including gestation, birth weight, feeding pattern and family or personal history of risk factors for obesity. The study was approved by the Joint Chinese University of Hong Kong New Territories East Cluster Clinical Research Ethics Committee and the Ethics Committee of the Department of Health of the Hong Kong Government.

\section{Measurement of growth parameters}

A team of 8 trained research staff visited the selected schools on a pre-arranged date to collect the anthropometric data. All instruments were standardised before the examination and the balances were zero calibrated. Standing height without shoes was measured twice using a Harpenden Stadiometer (Holtain, UK) to the nearest 0.1 $\mathrm{cm}$. Body weight was measured with the lightest clothing to the nearest $0.1 \mathrm{~kg}$ by an electronic weighting scale (Tanita BF-522, Japan). WC was measured midway between the lowest rib and the superior border of the iliac crest with an inelastic measuring tape at the end of normal expiration to the nearest $0.1 \mathrm{~cm}$. The intra-class (withinobserver) correlation coefficients, based on pairs of replicate measurements made by the same observer on 100 subjects on the same day, were 0.998 for weight and height, 0.997 for WC. All data were checked

Table I: A summary of population studies on children's waist circumference

\begin{tabular}{lllll}
\hline Countries & Sample size & Age range & Year of data & Authors/publication year \\
\hline Italya $^{\mathrm{a}}$ & F I4I8, M I440 & $6-14$ & 1993 & Zannolli et al., 1996 [19] \\
Spain $^{\mathrm{b}}$ & F 659, M 70I & $6-14.9$ & 1996 & Moreno et al., 1999 [20] \\
Cyprus $^{\mathrm{a}}$ & F I2I4, M I258 & $6-17$ & $1999-2000$ & Savva et al., 200I [2I] \\
UK $^{\mathrm{b}}$ & F 3585, M 4770 & $5-16.9$ & 1988 & McCarthy et al., 200I [22] \\
Canadac $^{\text {USAd }}$ & F I524, M I540 & $10.5-18.5$ & 1981 & Katzmarzyk, 2004 [23] \\
Netherlands $^{\mathrm{b}}$ & F 4944, M 4769 & $2-18$ & $1988-94$ & Fernandez et al., 2004 [24] \\
Australia $^{\mathrm{a}}$ & F 7018, M 7482 & $0-21$ & $1996-1997$ & Fredriks et al., 2005 [25] \\
Iran $^{\mathrm{b}}$ & F 4I62, M 4277 & $7-15$ & 1985 & Eisenmann et al., 2005 [26] \\
Present studyb & F I0858, M I0253 & $6-18$ & $2003-2004$ & Kelishadi et al., 2007 [27]
\end{tabular}

WC measured at a at umbilical level, b midway between the lowest rib and the superior border of the iliac crest, ${ }^{c}$ at the point of noticeable waist

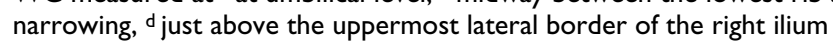


twice by two staff before data entry and then checked for inconsistencies.

\section{Statistics}

Statistical analyses were performed with SPSS 14.0 (SPSS Inc., Chicago, IL). Inter-correlations between BMI and WC as well as WHTR were assessed using Pearson correlation coefficients. Smoothed percentile curves were constructed for WC and WHTR by LMS method [33]. To compare our data with that of children from different ethnic populations, age- and gender-specific $10^{\text {th }}, 50^{\text {th }}$ and $90^{\text {th }}$ percentile curves from Britain and Iran were plotted with our data on the same chart. Mean WHTR of boys and girls were compared between the present study and the British survey using Student's t-test. All statistical tests were twosided. A p-value $<0.05$ was considered statistically significant.

\section{Results}

A total of 14,842 children participated in the study (7472 boys and 7370 girls). Sex and age-specific mean weight, height, BMI, WC and WHTR were obtained (Table 2) and then smoothed to develop sex- and age-specific WC and WHTR percentiles (Tables 3 and 4 and Figures 1 and 2). WC was relatively larger in boys than girls and increased with age, though to a smaller extent in girls after age $14 \mathrm{y}$. WHTR was slightly larger in boys than girls and in both sexes decreased with age but only up to age $14 \mathrm{y}$ and changed little further. Over the age range 14 to $18 \mathrm{y}$ WHTR 0.5 corresponded to the $95^{\text {th }}$ percentile for boys and the $97^{\text {th }}$ percentile for girls (Figure 2). WC correlated more closely than WHTR with BMI ( $r=0.93,0.91$ cf. 0.65, 0.59, for boys and girls respectively).

Comparison of the 10th, 50th and 90th percentile curves of WC with the 1988 British and 2003/4 Iranian data showed that both Hong Kong boys and girls were closer to British children except that our 90th percentile curve for boys was higher. Our 50th and 90th percentiles were lower than the Iranian curves (Figure 3). Comparison of WHTR data of Hong Kong boys and girls was made with the British data (the only dataset which provided WHTR for each year group) showed they are very similar with the mean differences ranging from only zero to 0.02 (Table 5).

\section{Discussion}

Sex and age-specific WC and WHTR percentiles, developed from data collected during $2005 / 6$ on a large and representative population of 14,842 Chinese children

Table 2: Sample sizes and mean and standard deviations (SD) for weight, height, BMI, waist circumference (WC) and waist-to-height ratio (WHTR) for Hong Kong Chinese children aged 6 to 18 y

\begin{tabular}{|c|c|c|c|c|c|c|c|}
\hline Sex & Age & $\mathbf{n}$ & Weight (kg) & Height (cm) & BMI & WC (cm) & WHTR \\
\hline Boys & 6 & 402 & $23.9(4.7)$ & $120.4(5.5)$ & $16.2(2.4)$ & $53.7(5.4)$ & $0.45(0.04)$ \\
\hline \multirow[t]{12}{*}{$(n=7472)$} & 7 & 520 & $26.4(6.1)$ & 125.7 (5.9) & $16.6(2.7)$ & $55.4(6.6)$ & $0.44(0.04)$ \\
\hline & 8 & 572 & $29.3(6.7)$ & I 30.7 (5.9) & $17.0(2.9)$ & $56.9(6.8)$ & $0.43(0.05)$ \\
\hline & 9 & 629 & $32.7(7.8)$ & $135.6(6.0)$ & $17.6(3.2)$ & $59.5(7.8)$ & $0.44(0.06)$ \\
\hline & 10 & 627 & $37.5(9.6)$ & $14 \mid .2(6.9)$ & $18.7(3.7)$ & $62.4(9.1)$ & $0.44(0.06)$ \\
\hline & 11 & 644 & $41.8(10.6)$ & I 47.3 (7.9) & $19.1(3.7)$ & $640(9.2)$ & $0.43(0.05)$ \\
\hline & 12 & 729 & 46.6 (11.9) & I54.I (8.6) & 19.4 (3.7) & $64.6(9.1)$ & $0.42(0.05)$ \\
\hline & 13 & 657 & $5 \mathrm{I.I}(1 \mathrm{I} .3)$ & $161.2(7.9)$ & $19.6(3.5)$ & $65.2(8.2)$ & $0.40(0.05)$ \\
\hline & 14 & 632 & $54,9(10.9)$ & $166.3(6.9)$ & $19.8(3.4)$ & $660(7.7)$ & $0.40(0.04)$ \\
\hline & 15 & 558 & $59.1(12.0)$ & $169.8(5.4)$ & $20.4(3.8)$ & $68.1(8.7)$ & $0.40(0.05)$ \\
\hline & 16 & 579 & 60.6 (11.1) & $170.9(5.8)$ & $20.7(3.4)$ & $68.8(8.2)$ & $0.40(0.05)$ \\
\hline & 17 & 553 & $61.5(11.0)$ & $171.9(5.7)$ & $20.8(3.4)$ & $69.4(7.8)$ & $0.40(0.05)$ \\
\hline & 18 & 370 & $62.3(11.0)$ & $17 \mid .7(5.6)$ & $21.1(3.3)$ & $70.1(7.6)$ & $0.41(0.04)$ \\
\hline Girls & 6 & 377 & $21.8(3.8)$ & II $8.7(5.1)$ & $15.4(1.9)$ & $51.3(4.2)$ & $0.43(0.03)$ \\
\hline \multirow[t]{12}{*}{$(n=7370)$} & 7 & 479 & $24.9(5.1)$ & $124.2(5.5)$ & $16.0(2.5)$ & $53.3(5.4)$ & $0.43(0.04)$ \\
\hline & 8 & 504 & $27.8(6.0)$ & $129.9(6.3)$ & $16.3(2.5)$ & $54.6(5.8)$ & $0.42(0.04)$ \\
\hline & 9 & 590 & $30.8(6.4)$ & I35.| (6.3) & $16.8(2.6)$ & $56.7(6.0)$ & $0.42(0.04)$ \\
\hline & 10 & 584 & $35.3(8.5)$ & $14 \mid .7(7.0)$ & $17.4(3.1)$ & $58.5(7.0)$ & $0.41(0.04)$ \\
\hline & 11 & 599 & $40.1(9.3)$ & 148.9 (7.0) & $19.0(3.2)$ & $60.2(6.9)$ & $0.40(0.04)$ \\
\hline & 12 & 750 & $44.1(9.4)$ & I53.I (6.2) & I8.7 (3.3) & $61.2(7.0)$ & $0.40(0.04)$ \\
\hline & 13 & 637 & $47.8(8.5)$ & $156.2(5.4)$ & $19.6(3.1)$ & $62.2(6.5)$ & $0.40(0.04)$ \\
\hline & 14 & 656 & $49.0(8.6)$ & I57.6 (5.4) & $19.7(3.0)$ & $62.3(6.2)$ & $0.40(0.04)$ \\
\hline & 15 & 600 & $50.5(9.1)$ & I58.3 (5.3) & $20.1(3.3)$ & $63.0(6.7)$ & $0.40(0.04)$ \\
\hline & 16 & 640 & 50.7 (8.9) & I 58.3 (5.3) & $20.2(3.3)$ & $63.2(6.4)$ & $0.40(0.04)$ \\
\hline & 17 & 568 & $51.4(9.2)$ & I58.9 (6.7) & $20.3(3.3)$ & $63.5(6.3)$ & $0.40(0.04)$ \\
\hline & 18 & 386 & $51.3(8.1)$ & $158.6(5.6)$ & $20.4(2.9)$ & $63.8(5.6)$ & $0.40(0.04)$ \\
\hline
\end{tabular}

Age: complete age, e.g. 6 y $=6.00-6.99$ y 
Table 3: Age- and sex-specific waist circumference percentile values $(\mathrm{cm})$ for Hong Kong Chinese children 6 to 18 y of age

\begin{tabular}{|c|c|c|c|c|c|c|c|c|c|c|c|}
\hline \multirow[b]{2}{*}{ Sex } & \multirow[b]{2}{*}{ Age } & \multirow[b]{2}{*}{$\mathbf{n}$} & \multicolumn{9}{|c|}{ Percentiles } \\
\hline & & & $3^{\text {rd }}$ & $5^{\text {th }}$ & $10^{\text {th }}$ & $25^{\text {th }}$ & $50^{\text {th }}$ & $75^{\text {th }}$ & $90^{\text {th }}$ & $95^{\text {th }}$ & $97^{\text {th }}$ \\
\hline \multirow[t]{13}{*}{ Boys } & 6 & 402 & 43.8 & 44.8 & 46.2 & 49.0 & 52.5 & 57.1 & 63.4 & 67.3 & 73.0 \\
\hline & 7 & 520 & 45.0 & 46.2 & 47.4 & 50.3 & 53.9 & 58.5 & 65.0 & 69.1 & 74.8 \\
\hline & 8 & 572 & 46.2 & 47.5 & 48.7 & 51.6 & 55.3 & 60.0 & 66.6 & 70.9 & 76.6 \\
\hline & 9 & 629 & 47.7 & 49.0 & 50.2 & 53.2 & 57.0 & 61.8 & 68.5 & 72.8 & 78.7 \\
\hline & 10 & 627 & 49.3 & 50.6 & 51.9 & 55.0 & 58.8 & 63.8 & 70.6 & 74.9 & 81.1 \\
\hline & 11 & 644 & 50.8 & 52.0 & 53.4 & 56.5 & 60.4 & 65.5 & 72.5 & 76.7 & 83.1 \\
\hline & 12 & 729 & 52.0 & 53.3 & 54.6 & 57.8 & 61.8 & 66.9 & 74.0 & 78.3 & 84.7 \\
\hline & 13 & 657 & 53.1 & 54.5 & 55.8 & 59.0 & 63.0 & 68.2 & 75.3 & 79.8 & 86.1 \\
\hline & 14 & 632 & 54.3 & 55.7 & 57.0 & 60.3 & 64.3 & 69.6 & 76.8 & 81.3 & 87.7 \\
\hline & 15 & 558 & 55.5 & 56.9 & 58.3 & 61.6 & 65.7 & 71.0 & 78.3 & 82.8 & 89.3 \\
\hline & 16 & 579 & 56.7 & 58.1 & 59.4 & 62.8 & 66.9 & 72.3 & 79.6 & 84.1 & 90.7 \\
\hline & 17 & 553 & 57.6 & 59.1 & 60.4 & 63.8 & 68.0 & 73.4 & 80.7 & 85.3 & 91.8 \\
\hline & 18 & 370 & 58.4 & 60.0 & 61.2 & 64.6 & 68.8 & 74.2 & 81.6 & 86.3 & 92.7 \\
\hline \multirow[t]{13}{*}{ Girls } & 6 & 377 & 43.3 & 44.2 & 45.2 & 47.5 & 50.3 & 53.8 & 58.4 & 61.5 & 64.9 \\
\hline & 7 & 479 & 44.6 & 45.5 & 46.5 & 48.9 & 51.7 & 55.3 & 60.0 & 63.1 & 66.7 \\
\hline & 8 & 504 & 45.9 & 46.9 & 47.9 & 50.3 & 53.2 & 56.8 & 61.6 & 64.8 & 68.5 \\
\hline & 9 & 590 & 47.2 & 48.3 & 49.3 & 51.7 & 54.7 & 58.4 & 63.4 & 66.6 & 70.4 \\
\hline & 10 & 584 & 48.6 & 49.7 & 50.7 & 53.2 & 56.2 & 60.1 & 65.1 & 68.4 & 72.4 \\
\hline & 11 & 599 & 50.0 & 51.1 & 52.2 & 54.7 & 57.8 & 61.7 & 66.9 & 70.1 & 74.3 \\
\hline & 12 & 750 & 51.3 & 52.3 & 53.4 & 56.0 & 59.2 & 63.1 & 68.4 & 71.7 & 76.0 \\
\hline & 13 & 637 & 52.3 & 53.4 & 54.5 & 57.1 & 60.3 & 64.3 & 69.7 & 72.9 & 77.4 \\
\hline & 14 & 656 & 53.0 & 54.2 & 55.3 & 57.9 & 61.1 & 65.2 & 70.6 & 73.8 & 78.4 \\
\hline & 15 & 600 & 53.6 & 54.8 & 55.8 & 58.5 & 61.7 & 65.8 & 71.3 & 74.4 & 79.2 \\
\hline & 16 & 640 & 54.0 & 55.2 & 56.2 & 58.9 & 62.2 & 66.3 & 71.8 & 74.8 & 79.7 \\
\hline & 17 & 568 & 54.3 & 55.6 & 56.6 & 59.3 & 62.6 & 66.7 & 72.2 & 75.1 & 80.2 \\
\hline & 18 & 386 & 54.6 & 55.9 & 56.9 & 59.6 & 62.9 & 67.1 & 72.6 & 75.4 & 80.6 \\
\hline
\end{tabular}

Age: completed age, e.g. 6 y $=6.00-6.99$ y

aged six to 18 y old, are presented. These charts are based on WC measured midway between lowest rib and superior iliac crest. Comparisons of WC data between different studies need to be undertaken with caution since WC may be measured at different sites and currently there is no agreement on which site is optimal [34]. In children, WC has been measured at five different sites: (i) midway between lowest rib and superior iliac crest (as in the present study) $[20,22,25,27]$; (ii) at the umbilical level $[19,21,28]$; (iii) at the narrowest point of the torso [23]; (iv) at the level of the right upper iliac crest [24]; and (v) at the level of $2 \mathrm{~cm}$ above the umbilicus [35]. WC measures at these different sites in children have not been formally compared. WC measurements in adults taken at four different sites have been compared and shown to provide slightly different, albeit highly reproducible data, that each correlate significantly with total and central body fat [34]. If WC is to become an important public health assessment tool of central obesity in both adults and children, international agreement about measurement site is required.
In the study, we compared Hong Kong children's WC with data from Britain and Iran where the method of measuring WC was the same as our study. The Iranian children's $50^{\text {th }}$ and $90^{\text {th }}$ percentile curves were much higher than those from Hong Kong and Britain. A previous report has shown that Iranian children have a high prevalence of high blood triglyceride (20\%) and low HDL-C (28\%) [6]. In contrast, our unpublished data has shown much lower prevalence of these risk factors in Hong Kong children. The Iranian paediatric population may provide an important opportunity to further study the relation between central obesity and dyslipidaemia.

Our study challenges the proposal that WHTR is a relatively age-independent measure that could obviate the need for age and growth-related reference standards in children. Our data show that WHTR is not independent of age in children under $14 \mathrm{y}$ old. Kahn and colleagues reported that WHTR appears to be independent of age and sex [36]. Ashwell and colleagues have proposed the use of an age-independent universal cut-off for WHTR of 0.5 [29]. This is despite their finding that the overall mean WHTR (with WC measured at the same site as in the 
Table 4: Age and sex specific percentiles of waist circumference/height ratio (WHTR) for Hong Kong Chinese children 6-18 y of age

\begin{tabular}{|c|c|c|c|c|c|c|c|c|c|c|c|}
\hline \multirow[b]{2}{*}{ Sex } & \multirow[b]{2}{*}{ Age } & \multirow[b]{2}{*}{$\mathbf{n}$} & \multicolumn{9}{|c|}{ Percentiles } \\
\hline & & & $3^{\text {rd }}$ & $5^{\text {th }}$ & $10^{\text {th }}$ & $25^{\text {th }}$ & $50^{\text {th }}$ & $75^{\text {th }}$ & $90^{\text {th }}$ & $95^{\text {th }}$ & $97^{\text {th }}$ \\
\hline \multirow[t]{13}{*}{ Boys } & 6 & 402 & 0.39 & 0.39 & 0.40 & 0.42 & 0.45 & 0.48 & 0.52 & 0.55 & 0.57 \\
\hline & 7 & 520 & 0.38 & 0.39 & 0.40 & 0.41 & 0.44 & 0.47 & 0.51 & 0.54 & 0.57 \\
\hline & 8 & 572 & 0.37 & 0.38 & 0.39 & 0.41 & 0.43 & 0.47 & 0.51 & 0.54 & 0.56 \\
\hline & 9 & 629 & 0.37 & 0.37 & 0.38 & 0.40 & 0.43 & 0.46 & 0.50 & 0.53 & 0.55 \\
\hline & 10 & 627 & 0.36 & 0.37 & 0.38 & 0.40 & 0.42 & 0.45 & 0.49 & 0.52 & 0.55 \\
\hline & 11 & 644 & 0.36 & 0.36 & 0.37 & 0.39 & 0.42 & 0.45 & 0.49 & 0.52 & 0.54 \\
\hline & 12 & 729 & 0.35 & 0.36 & 0.37 & 0.39 & 0.41 & 0.44 & 0.48 & 0.51 & 0.53 \\
\hline & 13 & 657 & 0.35 & 0.35 & 0.36 & 0.38 & 0.40 & 0.44 & 0.47 & 0.50 & 0.53 \\
\hline & 14 & 632 & 0.34 & 0.35 & 0.36 & 0.38 & 0.40 & 0.43 & 0.47 & 0.50 & 0.52 \\
\hline & 15 & 558 & 0.34 & 0.35 & 0.35 & 0.37 & 0.40 & 0.43 & 0.47 & 0.50 & 0.52 \\
\hline & 16 & 579 & 0.34 & 0.34 & 0.35 & 0.37 & 0.40 & 0.43 & 0.47 & 0.50 & 0.52 \\
\hline & 17 & 553 & 0.34 & 0.34 & 0.35 & 0.37 & 0.39 & 0.43 & 0.46 & 0.50 & 0.52 \\
\hline & 18 & 370 & 0.34 & 0.34 & 0.35 & 0.37 & 0.39 & 0.43 & 0.46 & 0.50 & 0.52 \\
\hline \multirow[t]{13}{*}{ Girls } & 6 & 377 & 0.38 & 0.38 & 0.39 & 0.41 & 0.43 & 0.46 & 0.49 & 0.51 & 0.52 \\
\hline & 7 & 479 & 0.37 & 0.38 & 0.39 & 0.40 & 0.42 & 0.45 & 0.48 & 0.50 & 0.52 \\
\hline & 8 & 504 & 0.37 & 0.37 & 0.38 & 0.40 & 0.42 & 0.44 & 0.47 & 0.49 & 0.51 \\
\hline & 9 & 590 & 0.36 & 0.37 & 0.38 & 0.39 & 0.41 & 0.44 & 0.47 & 0.49 & 0.50 \\
\hline & 10 & 584 & 0.36 & 0.36 & 0.37 & 0.39 & 0.41 & 0.43 & 0.46 & 0.48 & 0.50 \\
\hline & 11 & 599 & 0.35 & 0.36 & 0.37 & 0.38 & 0.40 & 0.43 & 0.46 & 0.48 & 0.50 \\
\hline & 12 & 750 & 0.35 & 0.35 & 0.36 & 0.38 & 0.40 & 0.42 & 0.45 & 0.47 & 0.49 \\
\hline & 13 & 637 & 0.35 & 0.35 & 0.36 & 0.37 & 0.39 & 0.42 & 0.45 & 0.47 & 0.49 \\
\hline & 14 & 656 & 0.34 & 0.35 & 0.36 & 0.37 & 0.39 & 0.42 & 0.45 & 0.47 & 0.49 \\
\hline & 15 & 600 & 0.34 & 0.35 & 0.36 & 0.37 & 0.39 & 0.42 & 0.45 & 0.47 & 0.49 \\
\hline & 16 & 640 & 0.34 & 0.35 & 0.36 & 0.37 & 0.39 & 0.42 & 0.45 & 0.47 & 0.49 \\
\hline & 17 & 568 & 0.34 & 0.35 & 0.36 & 0.37 & 0.39 & 0.42 & 0.45 & 0.47 & 0.49 \\
\hline & 18 & 386 & 0.34 & 0.35 & 0.36 & 0.37 & 0.39 & 0.42 & 0.45 & 0.47 & 0.49 \\
\hline
\end{tabular}

Age: completed age, e.g. $6 y=6.00-6.99 y$

present study) of 8135 British children aged 5 to $16 \mathrm{y}$ decreased with age from 0.47 to 0.42 in boys and from 0.46 to 0.41 in girls [31,37]. WHTR measures obtained in our study were slightly less than the 1988 British study. Our WHTR decreased with age up to $14 \mathrm{y}$ and then remained almost constant (Table 1, Figure 2). WHTR has now been correlated with CV risk markers in children in at least six studies $[6,28,30,35,36,38]$ and different WHTR cut-offs for predicting high CV risks in children at different ages were reported in one of them [6]. Ashwell's proposed 0.5 cut-off point for predicting CVS risk has yet to be tested by direct correlation with $\mathrm{CV}$ risk markers in children. Notably, few of our older children would be categorized as being at CV risk if this single 0.5 WHTR cut-off were used (Figure 2). This would conflict with our previous findings that a WC cut-off at the $85^{\text {th }}$ percentile for children under the age of $12 \mathrm{y}$ and at the $76^{\text {th }}$ percentile for those aged 13 to 18 y would predict CV risk $[11,39]$. For a WHTR cut-off of 0.5 to become a universal predictor of CV risk in children, further direct confirmatory evidence from comparative correlations with CV risk factors in children of different age and ethnic origins will be required.
BMI is the most widely used index to define children's weight status. Our finding that WC correlates considerably more closely than does WHTR with BMI in children is unsurprising given that $\mathrm{WC}$ and $\mathrm{BMI}$ increase, whereas WHTR decreases, with age. CV risk factors found in our previous study of around 2500 children drawn from the same population correlated in descending order of strength with WC, BMI and WHTR [11]. Others have reported that WC $[28,39-41]$ and WHTR $[28,30,36]$ correlate more strongly than does BMI with $\mathrm{CV}$ risk factors in children. No difference in the ability of WHTR and BMIfor-age to predict CV risk was found in one study [38]. These inconsistencies may reflect different methods of analysis, different ethnic populations and the relatively small differences between the related parameters.

A limitation of our study is that $7 \%$ of the primary and $10 \%$ of the secondary school students declined to participate. Reasons for non-participation were not recorded so it is not possible to determine whether non-participation resulted in any systematic bias. 

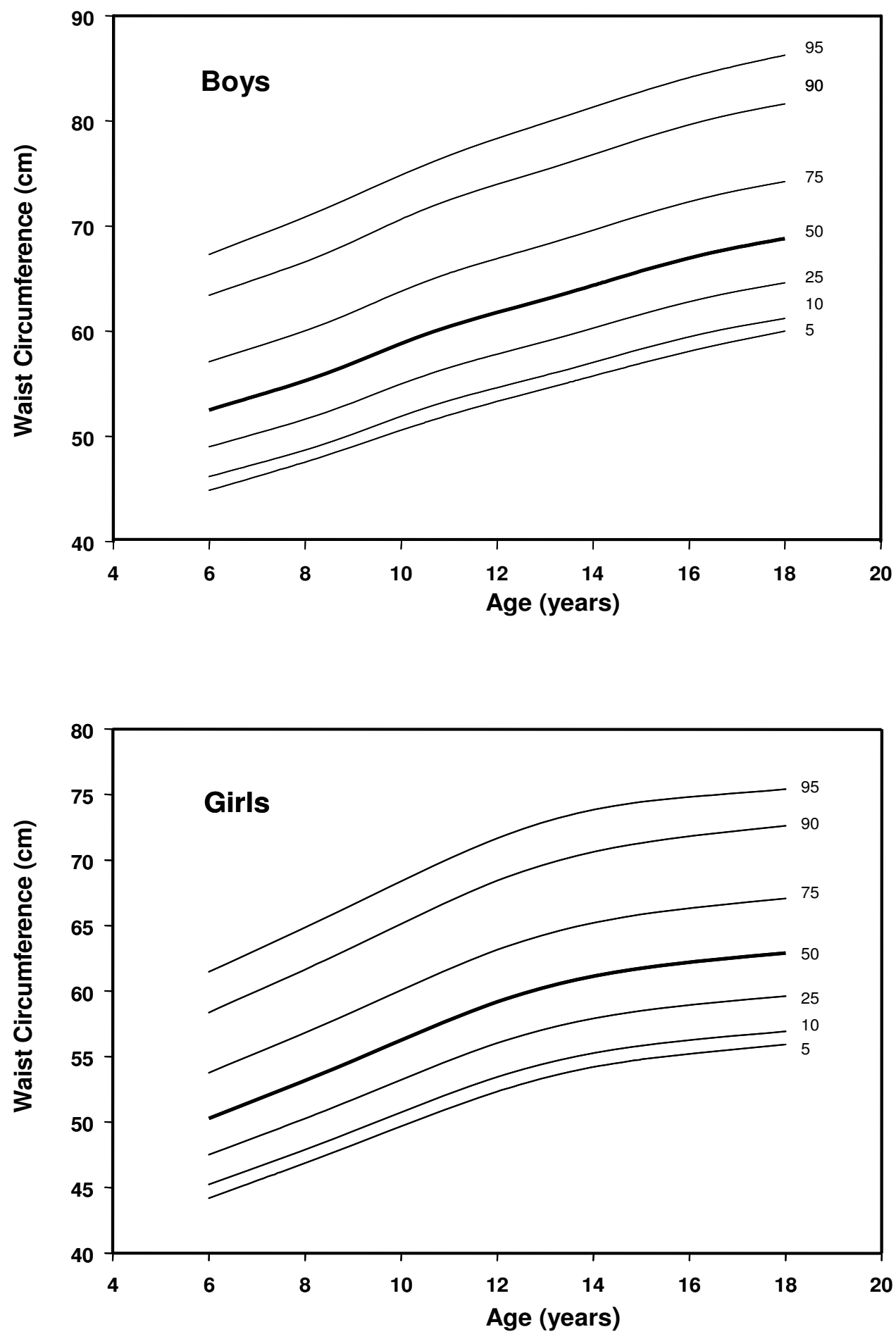

Figure I

Smoothed percentile curves of waist circumference for Hong Kong Chinese children aged 6 to I 8 y. 

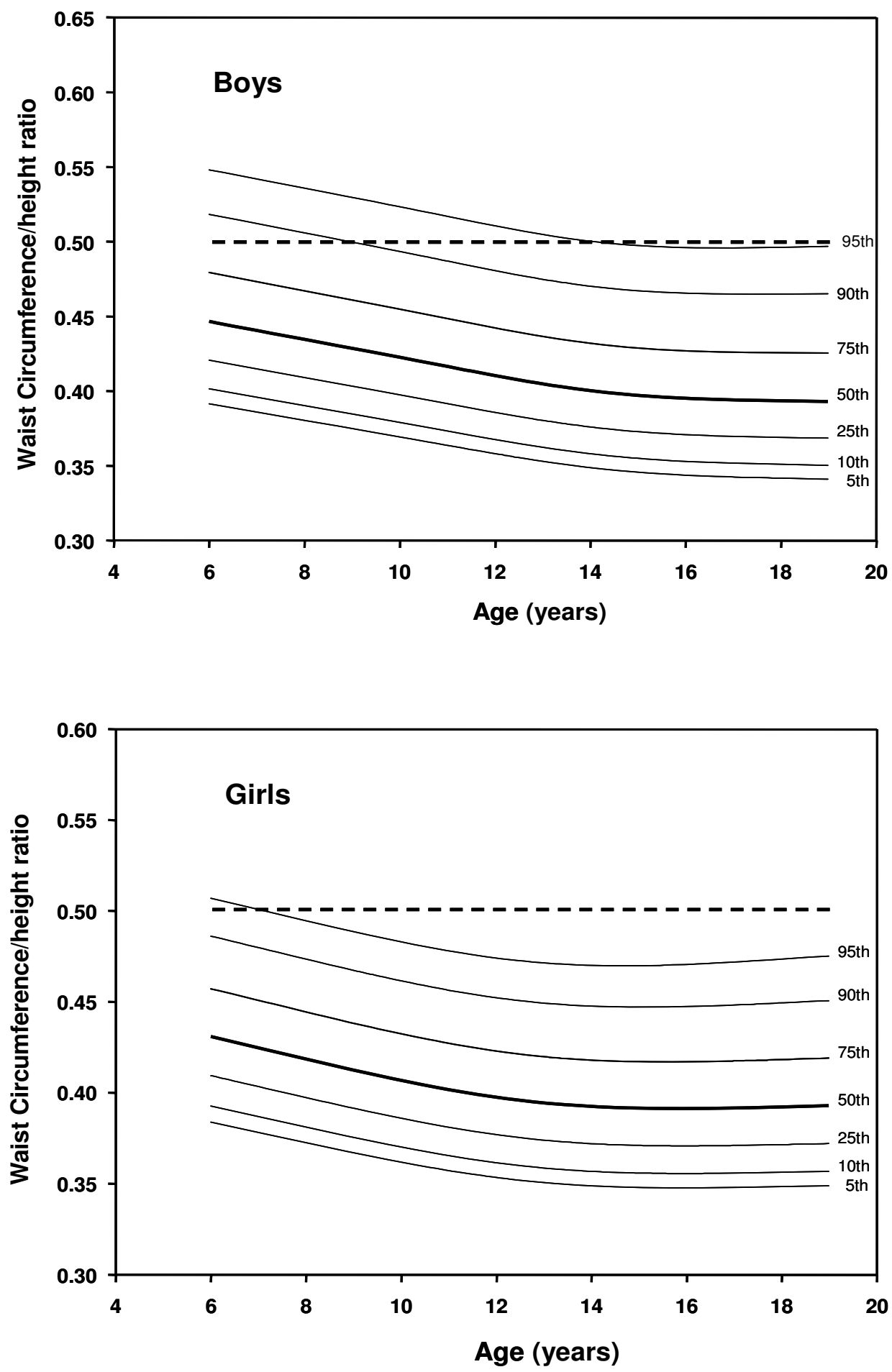

Figure 2

Smoothed percentile curves of waist circumference to height ratio (WHTR) for Hong Kong Chinese children aged 6 to 18 y. Dashed line shows superimposed universal cut-off value of 0.5 for all children. 
Table 5: Mean (SD) of waist height ratio at yearly intervals in Hong Kong and British children

\begin{tabular}{|c|c|c|c|c|c|c|}
\hline \multirow[b]{2}{*}{ Age $(y)$} & \multicolumn{2}{|c|}{ Boys } & \multirow[b]{2}{*}{$\mathrm{p}$-value } & \multicolumn{2}{|c|}{ Girls } & \multirow[b]{2}{*}{ P-value } \\
\hline & $\mathrm{HK}^{\mathrm{a}}$ & $U^{b}$ & & $\mathrm{HK}^{\mathrm{a}}$ & $\mathrm{UK}^{\mathrm{c}}$ & \\
\hline 6 & $0.45(0.04)$ & $0.45(0.03)$ & 0.999 & $0.43(0.03)$ & $0.45(0.03)$ & $<0.0001$ \\
\hline 7 & $0.44(0.04)$ & $0.44(0.03)$ & 0.999 & $0.43(0.04)$ & $0.44(0.03)$ & $<0.0001$ \\
\hline 8 & $0.43(0.05)$ & $0.43(0.03)$ & 0.999 & $0.42(0.04)$ & $0.43(0.03)$ & $0.86 I$ \\
\hline 9 & $0.44(0.06)$ & $0.43(0.04)$ & 0.007 & $0.42(0.04)$ & $0.42(0.03)$ & 0.999 \\
\hline 10 & $0.44(0.06)$ & $0.43(0.04)$ & 0.005 & $0.4 I(0.04)$ & $0.4 I(0.04)$ & 0.999 \\
\hline 11 & $0.43(0.05)$ & $0.43(0.04)$ & 0.999 & $0.40(0.04)$ & $0.4 I(0.04)$ & $<0.0001$ \\
\hline 12 & $0.42(0.05)$ & $0.43(0.04)$ & 0.001 & $0.40(0.04)$ & $0.4 I(0.03)$ & $<0.0001$ \\
\hline 13 & $0.40(0.05)$ & $0.42(0.04)$ & $<0.0001$ & $0.40(0.04)$ & $0.4 I(0.03)$ & $<0.0001$ \\
\hline 14 & $0.44(0.05)$ & $0.42(0.04)$ & $<0.0001$ & $0.40(0.04)$ & $0.40(0.03)$ & 0.999 \\
\hline 15 & $0.40(0.05)$ & $0.42(0.04)$ & $<0.0001$ & $0.40(0.04)$ & $0.40(0.03)$ & 0.999 \\
\hline 16 & $0.40(0.05)$ & $0.42(0.04)$ & $<0.0001$ & $0.40(0.04)$ & $0.4 I(0.03)$ & $<0.0001$ \\
\hline
\end{tabular}

aHong Kong data collected in 2005-2006, bUK boys' data collected in 1977, and c UK girls' data collected in 1987

\section{Conclusion}

Reference values and percentile curves for WC and WHTR of Chinese children and adolescents are provided in the study. Both WC and WHTR were age dependent. As a public health tool, WHTR does not on present evidence offer major advantages over WC for children. WC, measured at an agreed site and interpreted against appropriate established reference standards, remains the simplest clinical measure of central obesity for the prediction of CV risk in children. For standards based on WC and WC-derived parameters to be of general public health and research use for international comparisons, it will be important that a single defined site be agreed at which to measure WC.

\section{Competing interests}

The authors declare that they have no competing interests.

\section{Authors' contributions}

RYTS, EASN and AML prepared the proposal and supervised the study. HKS coordinated the study, assisted in the supervision of data collection, and took part in the statistical work. KCC took active part in the data analysing. JATY and CWLK helped in data collection and develop the protocol. PCN and TFF made substantial contributions to the conception of the study and revising the manuscript. All authors read and approved the final manuscript.

\section{Acknowledgements}

We thank the school principals, teachers, parents and students that participated in the study. We thank Professor AH Henderson, Emeritus Professor of Cardiology, at the University of Wales, College of Medicine for his critical review of the manuscript. This research project received financial support from Departmental funds and the Hong Kong Paediatric Society.

\section{References}

I. Despres JP, Moorjani S, Lupien PJ, Tremblay A, Nadeau A, Bouchard $\mathrm{C}$ : Regional distribution of body fat, plasma lipoproteins, and cardiovascular disease. Arteriosclerosis 1990, 10:497-5II.
2. Han TS, van Leer EM, Seidell JC, Lean ME: Waist circumference action levels in the identification of cardiovascular risk factors: prevalence study in a random sample. BMJ 1995, 31 I: I 40I-I 405.

3. Kahn HS, Valdez R: Metabolic risks identified by the combination of enlarged waist and elevated triacylglycerol concentration.[see comment]. Am J Clin Nutr 2003, 78:928-934.

4. Freedman DS, Dietz WH, Srinivasan SR, Berenson GS: The relation of overweight to cardiovascular risk factors among children and adolescents: the Bogalusa Heart Study. Pediatr 1999, 103: II75-I I82.

5. Maffeis C, Pietrobelli A, Grezzani A, Provera S, Tato L: Waist circumference and cardiovascular risk factors in prepubertal children. Obes Res 200I, 9:179-187.

6. Kelishadi R, Gheiratmand R, Ardalan G, Adeli K, Mehdi GM, Mohammad RE, Majdzadeh R, Delavari A, Shariatinejad K, Motaghian M, Heshmat R, Heidarzadeh A, Barekati H, Sadat Mahmoud-Arabi M, Mehdi RM, CASPIAN Study Group: Association of anthropometric indices with cardiovascular disease risk factors among children and adolescents: CASPIAN Study. Int J Cardiol 2007, I I 7:340-348.

7. Bjorntorp P: Obesity and risk of cardiovascular disease. Acta Medica Scandinavica 1985, 21 8: 145-147.

8. Yusuf S, Hawken S, Ounpuu S, Bautista L, Franzosi MG, Commerford P, Lang CC, Rumboldt Z, Onen CL, Lisheng L, Tanomsup S, Wangai P Jr, Razak F, Sharma AM, Anand SS: Obesity and the risk of myocardial infarction in $\mathbf{2 7 , 0 0 0}$ participants from 52 countries: a case-control study. Lancet 2005, 366:1640-1649.

9. Esmaillzadeh A, Mirmiran P, Azizi F: Clustering of metabolic abnormalities in adolescents with the hypertriglyceridemic waist phenotype. Am J Clin Nutr 2006, 83:36-46.

10. Hirschler V, Aranda C, Calcagno ML, Maccalini G, Jadzinsky M: Can waist circumference identify children with the metabolic syndrome? Arch Pediatr Adolesc Med 2005, 159:740-744.

II. Sung RY, Yu CC, Choi KC, McManus A, Li AM, Xu SL, Chan D, Lo $A F$, Chan JC, Fok TF: Waist circumference and body mass index in Chinese children: cutoff values for predicting cardiovascular risk factors. Int J Obesity 2007, 3 I:550-558.

12. McKeigue PM, Shah B, Marmot MG: Relation of central obesity and insulin resistance with high diabetes prevalence and cardiovascular risk in South Asians. Lancet I991, 337:382-386.

13. Lee ZS, Chan JC, Yeung VT, Chow CC, Lau MS, Ko GT, Li JK, Cockram CS, Critchley JA: Plasma insulin, growth hormone, cortisol, and central obesity among young Chinese type 2 diabetic patients. Diabetes Care 1999, 22: 1450-1457.

14. Novotny R, Daida YG, Grove JS, Le Marchand L, Vijayadeva V: Asian adolescents have a higher trunk:peripheral fat ratio than Whites. INutr 2006, 136:642-647.

15. He Q, Horlick M, Thornton J, Wang J, Pierson RN Jr, Heshka S, Gallagher $D$ : Sex and race differences in fat distribution among Asian, African-American, and Caucasian prepubertal children. J Clin Endocrinol Metab 2002, 87:2164-2170. 

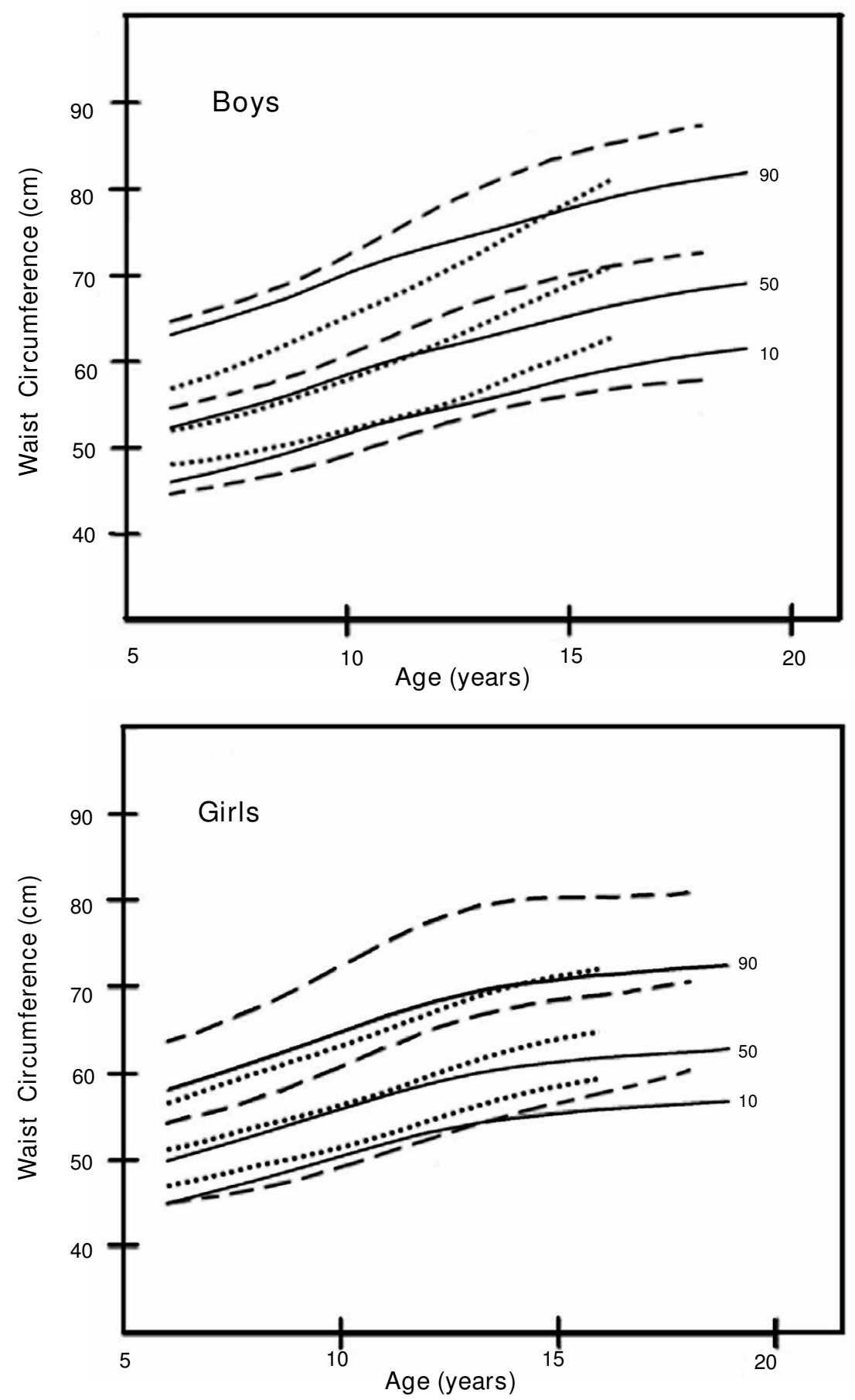

Figure 3

Comparison of smoothed percentile curves of waist circumference for UK, Iran and Hong Kong children. Hong Kong (2005-2006), _ _ _ $\operatorname{Iran}(2003-2004)$, ............. UK(I 978 \& 1988). 
16. Lean ME, Han TS, Morrison CE: Waist circumference as a measure for indicating need for weight management. BMJ 1995 , 3II:I58-16I.

17. World Health Organization: Preventing and managing the global epidemic. Report of a WHO consultation on obesity Geneva: World Health Organization (WHO/NUT/NCD/98.I); 1998

18. Ko GT, Tang JS: Waist circumference and BMI cut-off based on I 0-year cardiovascular risk: evidence for "central pre-obesity". Obesity 2007, I 5:2832-2839.

19. Zannolli R, Morgese G: Waist percentiles: a simple test for atherogenic disease? Acta Paediatrica 1996, 85: I368-I369.

20. Moreno LA, Fleta J, Mur L, Rodriquez G, Sarria A, Bueno M: Waist circumference values in Spanish children-gender related differences. Eur J Clin Nutr 1999, 53:429-433.

21. Savva SC, Kourides Y, Tornaritis M, Epiphaniou-Savva M, Tafouna P, Kafatos A: Reference growth curves for cypriot children 6 to I 7 years of age. Obes Res 200I, 9:754-762.

22. McCarthy HD, Jarrett KV, Crawley HF: The development of waist circumference percentiles in British children aged 5.0-I6.9 y. Eur J Clin Nutr 200I, 55:902-907.

23. Katzmarzyk PT: Waist circumference percentiles for Canadian youth I I-I 8 y of age. Eur J Clin Nutr 2004, 58: I O I I-I0I5.

24. Fernandez JR, Redden DT, Pietrobelli A, Allison DB: Waist circum ference percentiles in nationally representative samples of African-American, European-American, and MexicanAmerican children and adolescents. I Pediatr 2004 I 45:439-444.

25. Fredriks AM, van Buuren S, Fekkes M, Verloove-Vanhorick SP, Wit JM: Are age references for waist circumference, hip circumference and waist-hip ratio in Dutch children useful in clinical practice? Eur J Pediatr 2005, 164:216-222.

26. Eisenmann JC: Waist circumference percentiles for 7- to I5year-old Australian children. Acta Paediatrica 2005 , 94: I I82-II85.

27. Kelishadi R, Gouya MM, Ardalan G, Hosseini M, Motaghian M, Delavari A, Majdzadeh R, Heidarzadeh A, Mahmoud-Arabi MS, Riazi MM, CASPIAN Study Group: First reference curves of waist and hip circumferences in an Asian population of youths: CASPIAN study. J Trop Pediatr 2007, 53: I58-I64.

28. Savva SC, Tornaritis M, Savva ME, Kourides Y, Panagi A, Silikiotou N, Georgiou C, Kafatos A: Waist circumference and waist-toheight ratio are better predictors of cardiovascular disease risk factors in children than body mass index. Int ] Obes Relat Metab Disord 2000, 24: I453-I458.

29. Ashwell M, Lejeune S, McPherson K: Ratio of waist circumference to height may be better indicator of need for weight management. $B M J$ 1996, 3 I 2:377

30. Hara M, Saitou E, Iwata F, Okada T, Harada K: Waist-to-height ratio is the best predictor of cardiovascular disease risk factors in Japanese schoolchildren. J Atheroscler Thromb 2002 , 9:127-132.

31. Ashwell M: Waist to height ratio and the AshwellR shape chart could predict the health risks of obesity in adults and children in all ethnic groups. Nutrition Food Science 2005 , 35:359-364.

32. Leung SS, Cole TJ, Tse LY, Lau JT: Body mass index reference curves for Chinese children. Ann Hum Biol 1998, 25:169-174.

33. Cole TJ, Green PJ: Smoothing reference centile curves: the LMS method and penalized likelihood. Stat Med 1992 I I:I305-1319.

34. Wang J, Thornton JC, Bari S, Williamson B, Gallagher D, Heymsfield SB, Horlick M, Kotler D, Laferrere B, Mayer L, Pi-Sunyer FX, Pierson RN Jr: Comparisons of waist circumferences measured at 4 sites. Am J Clin Nutr 2003, 77:379-384

35. Weili Y, He B, Yao H, Dai J, Cui J, Ge D, Zheng Y, Li L, Guo Y, Xiao K, Fu X, Ma D, Weili Y, He B, Yao H, Dai J, Cui J, Ge D, Zheng Y, L $\mathrm{L}$, Guo $\mathrm{Y}$, Xiao K, Fu X, Ma D: Waist-to-height ratio is an accurate and easier index for evaluating obesity in children and adolescents. Obesity 2007, 15:748-752.

36. Kahn HS, Imperatore G, Cheng YJ: A population-based comparison of BMI percentiles and waist-to-height ratio for identifying cardiovascular risk in youth. J Pediatr 2005, I 46:482-488.

37. McCarthy HD, Ashwell M: A study of central fatness using waistto-height ratios in UK children and adolescents over two decades supports the simple message-'keep your waist cir- cumference to less than half your height'. Int J Obesity 2006 , 30:988-992

38. Freedman DS, Kahn HS, Mei Z, Grummer-Strawn LM, Dietz WH, Srinivasan SR, Berenson GS: Relation of body mass index and waist-to-height ratio to cardiovascular disease risk factors in children and adolescents: the Bogalusa Heart Study. Am J Clin Nutr 2007, 86:33-40.

39. Ng VWS, Kong APS, Choi KC, Ozaki R, Wong GWK, So WY, Tong PCY, Sung RYT, Shirley Xu, Chan M, Ho CS, Lam CWK, Chan JCN: Use of Body Mass Index and Waist Circumference to Predict Clustering of Cardiovascular Risk Factors in Hong Kong Chinese Adolescents. Obes Res 2007, 15:494-503.

40. Janssen I, Katzmarzyk PT, Ross R: Waist circumference and not body mass index explains obesity-related health risk. Am J Clin Nutr 2004, 79:379-384.

4I. Moreno LA, Pineda I, Rodriguez G, Fleta J, Sarria A, Bueno M: Waist circumference for the screening of the metabolic syndrome in children. Acta Paediatrica 2002, 91:1307-1312.

\section{Pre-publication history}

The pre-publication history for this paper can be accessed here:

http://www.biomedcentral.com/1471-2458/8/324/pre pub
Publish with Bio Med Central and every scientist can read your work free of charge

"BioMed Central will be the most significant development for disseminating the results of biomedical research in our lifetime. "

Sir Paul Nurse, Cancer Research UK

Your research papers will be:

- available free of charge to the entire biomedical community

- peer reviewed and published immediately upon acceptance

- cited in PubMed and archived on PubMed Central

- yours - you keep the copyright
BiolMedcentral 